Document downloaded from:

http://hdl.handle.net/10251/171222

This paper must be cited as:

Tian, P.; Antonino Daviu, JA.; Platero, C.; Dunai, L. (2021). Detection of Field Winding Faults in Synchronous Motors via Analysis of Transient Stray Fluxes and Currents. IEEE Transactions on Energy Conversion. 36(3):2330-2338.

https://doi.org/10.1109/TEC.2020.3041643

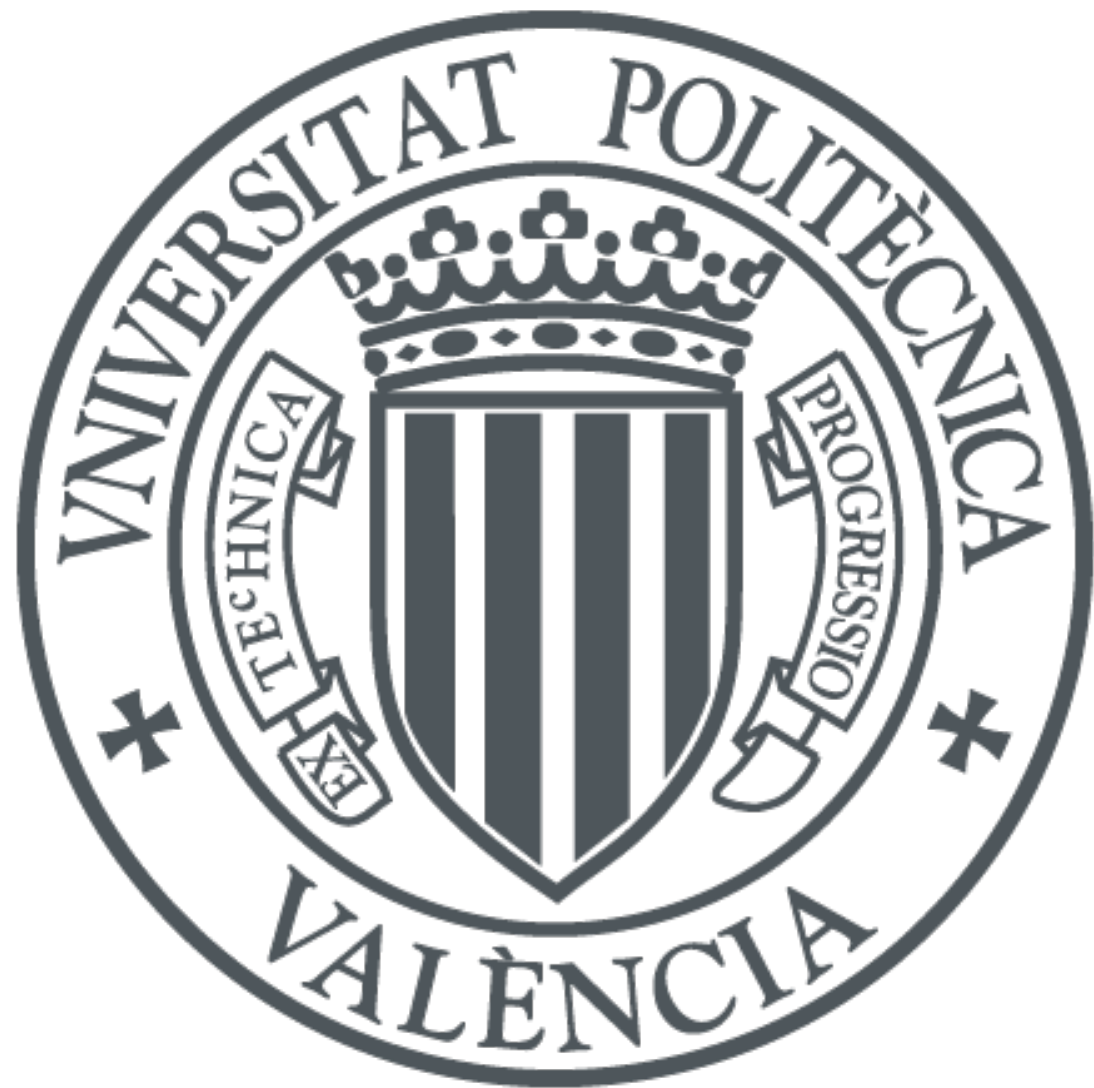

The final publication is available at

https://doi.org/10.1109/TEC.2020.3041643

Copyright Institute of Electrical and Electronics Engineers

Additional Information

(c) 2021 IEEE. Personal use of this material is permitted. Permission from IEEE must be obtained for all other uses, in any current or future media, including reprinting/republishing this material for advertising or promotional purposes, creating new collective works, for resale or redistribution to servers or lists, or reuse of any copyrighted component of this work in other works. 


\title{
Detection of Field Winding Faults in Synchronous Motors via Analysis of Transient Stray Fluxes and Currents
}

\author{
P. Tian, J. Antonino-Daviu, Senior Member, IEEE, C.A. Platero, Senior Member, IEEE, and L.Dunai, \\ Member, IEEE
}

\begin{abstract}
The detection of rotor failures in synchronous motors is a matter of primordial interest in many industrial sites where these machines are critical assets. However, due to the particular operation of these motors, most conventional techniques relying on steady-state analysis, commonly used in other electric machines, are not applicable to such motors. In this context, it has been recently proven that the analysis of different quantities under transient operation of the motor and, more specifically, under motor starting can provide crucial information for the diagnosis of many faults. This work proposes the timefrequency analysis of stray fluxes and currents to detect field winding faults in synchronous motors. The potential consequences of this fault can be catastrophic for the motor integrity, so that the detection of its presence in its early stages can be of critical importance for the industry. The results included in this paper prove the usefulness of the transient analysis of such non-invasive quantities not only to detect the presence of the field winding fault but also to set a starting point to determine its severity.
\end{abstract}

Index Terms - Synchronous motors, maintenance, fault diagnosis, reliability, transient analysis, time-frequency transforms, starting, field winding.

\section{INTRODUCTION}

$\mathrm{I}_{\mathrm{a}}^{\mathrm{N}}$ industry, Synchronous Motors (SM) are not so widespread as other rotating electrical machines, such as induction motors. However, they often participate in some high output applications (typically above $1 \mathrm{MW}$ ), in which they are critical elements. This is due to the fact that they have some interesting advantages that make them an attractive option for those power ranges, such as higher efficiency or possibility of power factor regulation [1]-[2]. Unexpected failures in such machines can lead to production downtimes due to unplanned shutdowns, which can yield huge economic losses for the corresponding companies [3]. Due to this fact, it is primordial to apply predictive maintenance techniques that are able to detect potential failures when these are still at their early stages of development. The problem is that the research devoted to these machines has been much more reduced than that focused on

This work was supported by the Spanish 'Ministerio de Ciencia Innovación y Universidades' and FEDER program in the framework of the 'Proyectos de I+D de Generación de Conocimiento del Programa Estatal de Generación de Conocimiento y Fortalecimiento Científico y Tecnológico del Sistema de $\mathrm{I}+\mathrm{D}+\mathrm{i}$, Subprograma Estatal de Generación de Conocimiento' (ref: PGC2018-095747-B-I00).

J. A. Antonino-Daviu is with the Instituto Tecnologico de la Energia, Universitat Politècnica de València, Camino de Vera s/n, 46022, Valencia, SPAIN (joanda@die.upv.es). other machines such as induction motors, a fact that has led to a scarcity of available techniques for monitoring the condition of certain machine parts.

One of the parts of the SM that is more sensible to potential faults is the rotor. Previous works have proven the possible occurrence of different failures in this part of the machine. In this regard, damages in the damper cage of SM were reported in several works. It was shown there that this element, which plays a crucial role for the starting of such machines (enabling to start them in an asynchronous manner), among other functions, may be deteriorated due to several reasons. In [4][5], a catastrophic failure in the damper of a critical 33MW SM was reported. This fault implied a plant shutdown of near four weeks as well as losses that amounted for several million $€$.

On the other hand, field winding faults in SM have been also reported in other works. The field winding insulation is often subjected to hard conditions under operation (centrifugal forces, vibrations, contamination, switching transients [6]-[8]). All these factors may act together and compromise its integrity. The degradation of the interturn insulation may lead to shorted turns that may have negative repercussions on the motor performance, due to the alteration of the flux distribution and nonuniform thermal expansion, together with mechanical asymmetry [9]. If the fault gets worse, it may even lead to more severe repercussions including forced motor outages.

There are some off-line methods that are able to detect shorted turns in the field winding (impedance measurement, pole drop test, surge oscillography...) [9] but they have important practical limitations and must be developed when the motor is out of operation, a fact that limits their applicability in many machines working under continuous duty cycles.

Taking the constraints of offline methods into consideration, online techniques have been also proposed over these recent years to detect developing failures in the field winding. In this regard, methods based on monitoring circulating currents in machines with parallel branches in the stator winding [10]-[11], vibration spectrum analysis [12], as well as shaft voltage [13]

P. Tian and C.A. Platero are with Universidad Politécnica de Madrid, Calle de José Gutierrez Abascal no 2, 28006 Madrid, SPAIN (tpf1213@gmail.com and carlosantonio.platero@upm.es)

L. Dunai is with the Centro de Investigación en Tecnologías Gráficas, Universitat Politècnica de València, Camino de Vera s/n, 46022, Valencia, SPAIN (e-mail: ladu@upv.es). 
or field winding temperature analysis [14] have been also proposed, among other methods. However, none of these approaches has been successful enough to be adopted in real industrial applications due to their limited applicability or lack of reliability.

The study of the airgap leakage flux to obtain valuable information for the diagnosis of field winding faults in SM has been proposed by several authors [15]-[18]. These approaches are mainly based on installing internal flux probes near the stator slots; their practical implementation has been mainly circumscribed to large synchronous generators and their reliability has been not demonstrated in a number of cases. More recently, the study of the airgap flux under starting has been proposed for detecting field winding faults in salient pole SM [9]. This method is based on tracking the evolutions of fault harmonics of interest in the time frequency analyses of airgap flux signals. Although the approach brings the advantage of detecting the failure without motor disassembly, still implies the intrusive installation of internal sensors for airgap flux measurement.

The present work proposes the combined application of strayflux signals and currents under starting for the detection of field winding faults in SM. The joint analysis of these quantities brings the additional advantage that is non-intrusive and that, in combination, they can enhance the diagnosis reliability. Timefrequency analyses of such quantities registered under the asynchronous starting of the machine is followed by the identification of characteristic signatures created by faultrelated harmonics. Moreover, potential fault severity indicators relying on the evaluation of the energy density in particular time-frequency regions of the resulting analyses are proposed. The results show that the study of these non-invasive quantities under starting provides very reliable information for the diagnosis of the fault, since it relies on multiple components. This confirms the potential of the approach to be implemented in portable electric motors condition monitoring devices.

\section{DETECTION OF FIELD WINDING FAULT COMPONENTS UNDER STARTING}

Previous works have shown that, in the case of field winding faults in SM, some specific components are amplified in the airgap flux [9]. More specifically, if appropriate airgap flux sensors are installed in the machine, components $f_{f}$ at frequencies given by (1) are induced in the electromotive force $e$ signal induced by the airgap flux in those sensors, where $k_{l}$ is a positive integer, $s$ is the slip, $p$ is the number of pole pairs of the motor and $f_{s}$ is the supply frequency. Following a similar reasoning to that carried out in [9], these components would also raise in the voltage signal induced in external stray flux sensors due to the once per rotor revolution fluctuation caused by the local flux that is produced by the fault loop current in the pole with the short circuit.

$$
f_{f}=f_{s} \pm k_{1} \cdot f_{r}=f_{s} \cdot\left(1 \pm k_{1} \cdot \frac{(1-s)}{p}\right)
$$

Moreover, note that, in the case of salient pole synchronous motors, the pole saliency effect introduces additional components in the spectrum of the electromotive forces (emf) induced in the airgap flux sensors, as proven in previous works [9]. These components are due to the flux fluctuation that takes place every time the salient poles pass the fixed search coil $(2 p$ times per rotor revolution) and will be also present in the stray flux [9]. These components $f_{s a}$ are given by (2), where $k_{2}$ is another positive integer. The components $f_{f}$ and $f_{s a}$ overlap when $k_{l}=2 \cdot p \cdot k_{2}[9]$.

$$
f_{s a}=f_{s} \cdot\left(1 \pm 2 \cdot k_{2} \cdot(1-s)\right)
$$

Both components $f_{f}$ and $f_{s a}$ are slip dependent. Therefore, during the asynchronous starting of a SM, as the slip $s$ changes (between 1 when the stator winding is fed and near 0 when the synchronization takes place after the field winding is supplied), they will vary with time. These evolutions yield particular timefrequency trajectories that were characterized in previous works [9]. These theoretical trajectories, extracted with proper timefrequency transforms, are represented in Fig. 1 for different values of $\mathrm{k}_{1}$ and $k_{2}$. As commented in [9], the components at $f_{f}$ that do not overlap with $f_{s a}$ would be only observed at startup, while the current is induced in the shorted loop of the field winding (i.e. when the rotor speed is different from the synchronous speed).

Note that the time-frequency trajectories depicted in Fig. 1 correspond to the components present in the emf signals induced in internal airgap flux sensors. One of the objectives of the present work is to analyze which of these components are present in the emf induced by the stray flux in external sensors attached to the motor frame. The advantage of considering stray flux sensors is that they do not require an intrusive installation, as the airgap flux sensors do, and they can be attached at any time.

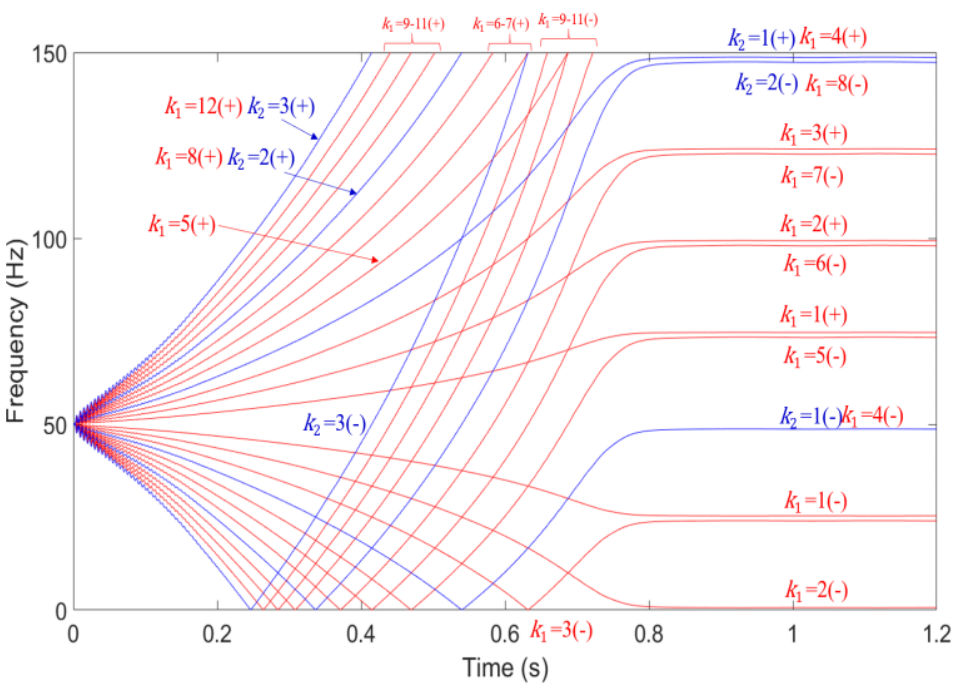

Fig. 1. Theoretical time-frequency evolutions of the airgap flux components linked to field winding faults $f_{f}$ and saliency effect $f_{s a}$ during the asynchronous starting of a SM.

On the other hand, some of the components depicted in Fig.1 are also present in the time-frequency analysis of the stator startup current demanded by the SM during the asynchronous startup. In this regard, in previous works [5], it was shown that the saliency components present at $f \cdot(1 \pm 2 \cdot k \cdot s)$ will appear. This may be also amplified by other faults as damper damages [5]. On the other hand, the components given by (1) will also appear 
in these time-frequency maps in the case of field winding faults but, in this case, they are also particularly sensitive to other mechanical problems in the own machine (e.g. misalignments) or in the driven load (unbalances) [19].

\section{EXPERIMENTS}

Several tests were carried out in the laboratory in a salient pole synchronous machine with the characteristics specified in Table I. The complete experimental setup can be seen in Fig. 2.

The synchronous machine was used as a motor and it was started by supplying it directly from the grid by a 3-phase adjustable voltage source through a contactor (the own rotor core assumed the function of the damper, enabling the asynchronous starting). The motor was mechanical coupled to an induction machine, used as generator. The simplified diagram of the experimental setup is displayed in Fig. 3.

In order to limit the current in the field winding during the starting of the synchronous motor, a starting resistor $R_{S}$ is connected to the field winding through a slip ring and brushes system (Fig. 3).

Moreover, this synchronous machine has four poles and the connections between them are accessible in a shaft hole. Therefore, the inter-turn rotor faults of various severities can be performed by the use of a rotating variable fault resistance $\mathrm{R}_{\mathrm{F}}$. Three different cases where performed: healthy machine, a complete pole short-circuited and a partial interturn fault in one pole. So, in the first case no resistor was connected $\left(\mathrm{R}_{\mathrm{F}}=\infty\right)$ while in the second case, the value of the resistor is zero $\left(\mathrm{R}_{\mathrm{F}}=\right.$ 0 ). In the last case, a resistor with the same resistance as one the pole was used $\left(\mathrm{R}_{\mathrm{F}}=2.7 \Omega\right)$. The connection of the resistor 2.7 $\Omega$ can be seen in Fig. 4

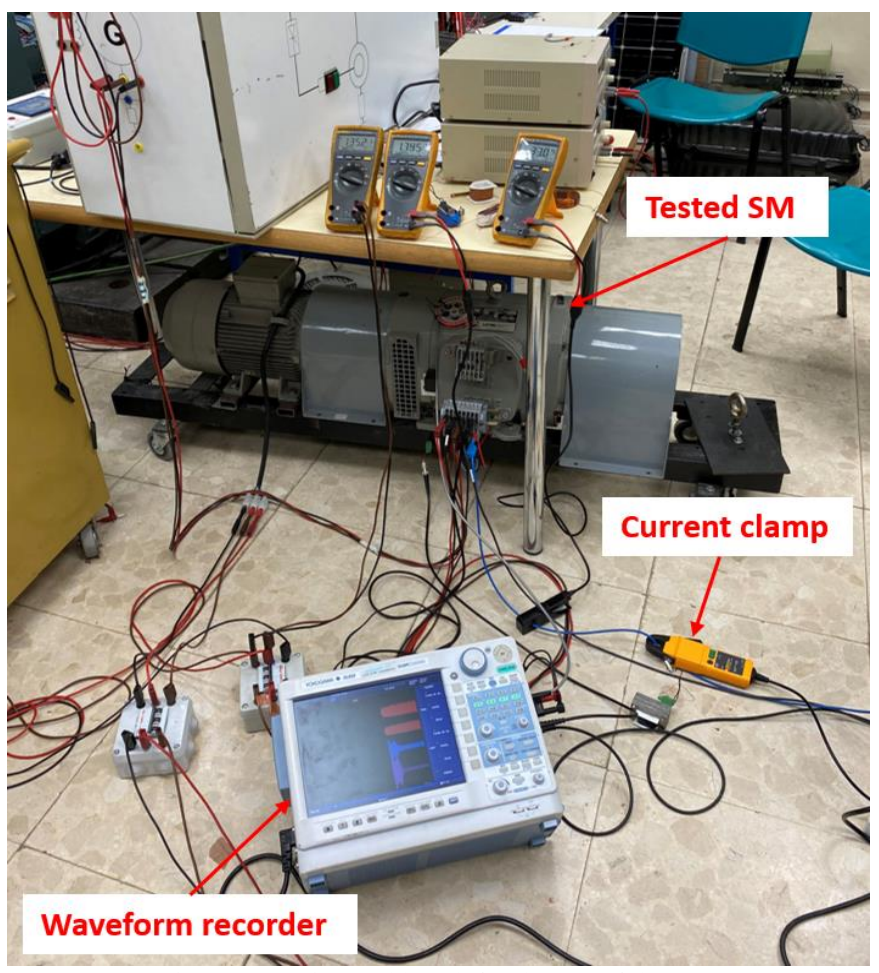

Fig. 2. Experimental bench for the test of the SM.

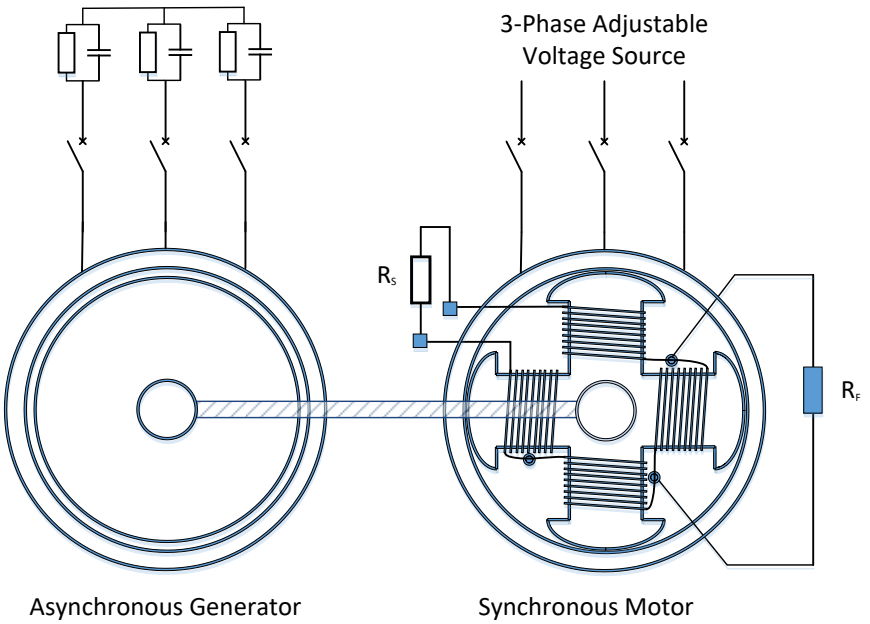

Fig. 3. Experimental bench simplified electric diagram.
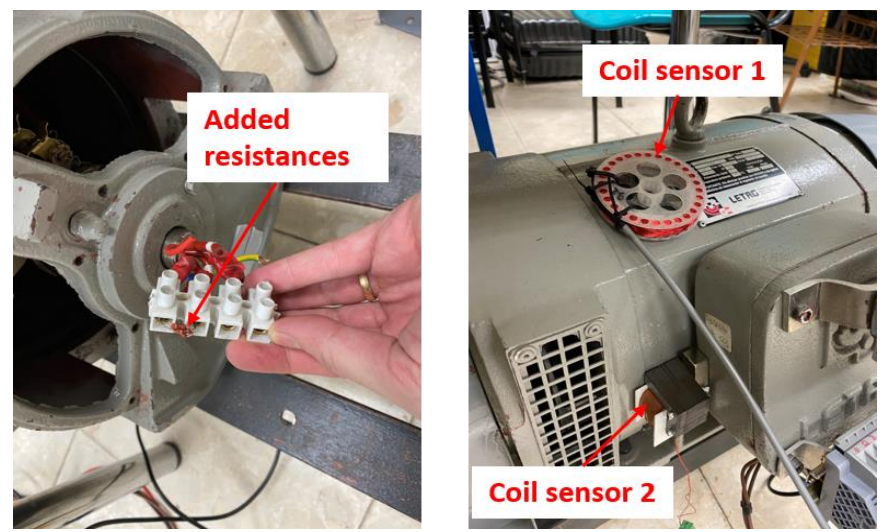

Fig. 4. Added resistances $\mathrm{R}_{\mathrm{F}}$ for the field winding fault and stray flux coil sensors.

During the starting of the machine the stray flux was recorded by two different stray flux sensors (Fig.4). Both sensors were attached to the motor frame, close to the stator iron core area (see Fig.4). The selected positions were taken as optimum for stray flux measurement, considering that the motor had a fan in the drive end and the exciter in the non-drive end. The first sensor (Fig.4. Coil sensor 1) is an air core coil with $N_{l}=1000$ turns, round shaped, which had an external diameter of $80 \mathrm{~mm}$ and an internal diameter of $39 \mathrm{~mm}$. The second one (Fig. 4. Coil sensor 2) is an iron core coil, the core of which was manufactured with standard E laminations of type EI-60. The total dimensions are $60 \times 25 \times 40 \mathrm{~mm}$ (length $\mathrm{x}$ width $\mathrm{x}$ height) and it had 200 turns. Further information about this flux sensor are detailed in [20].

TABLE I

SYNCHRONOUS MACHINE RATINGS

\begin{tabular}{lrr}
\hline Rated power & 3.4 & $\mathrm{kVA}$ \\
rpm & 1500 & \\
Rated voltage & 400 & $\mathrm{~V}$ \\
Rated current & 5.0 & $\mathrm{~A}$ \\
Phase & 3 & \\
Rated frequency & 50 & $\mathrm{~Hz}$ \\
IP & 21 & \\
Isolation Class & $\mathrm{F}$ & \\
Rated excitation voltage & 32 & $\mathrm{~V}$ \\
Rated excitation current & 2.90 & $\mathrm{~A}$ \\
Inertia & 0.041 & $\mathrm{kgm}^{2}$ \\
\hline
\end{tabular}


The first set of starting tests were performed with the machine unloaded, that is the induction machine stator was disconnected. Consequently, the induction machine only add inertia and demands mechanical losses during the starting process. The inertia of the motor is $0.015 \mathrm{kgm}^{2}$ and the mechanical losses of the test bench are $325 \mathrm{~W}$ at $1500 \mathrm{rpm}$. Furthermore, a set of loaded starting test was performed. In this last case, the induction machine terminals were connected to a resistive-capacity load and operated as an asynchronous generator. In this operation mode, the induction machine is magnetized by the capacitors connected in the stator. Therefore, there are induced voltages in the stator windings. The generated power is controlled by the resistors placed in parallel to the capacitors.

\section{Results: Time-FreQuenCy Plots}

Fig. 5 shows the time-frequency analyses of different quantities that were registered during the starting (unloaded motor) for three faulty conditions of the tested SM: healthy field winding, field winding fault with an added resistance of $2.7 \Omega$ and short-circuited pole. For each fault case, the depicted analyses correspond to four different quantities: 1) emf force induced by the stray flux in an external air-core flux sensor (coil sensor 1), 2) emf force induced by the stray flux in an iron-core flux sensor (coil sensor 2), 3) stator startup current and 4) rotor current, all of them under starting. The Short Time Fourier Transform (STFT) was employed in this work due to the simplicity of the tool and its availability in conventional software packages. An optimized window size was adjusted to be able to track all expected harmonic evolutions predicted in Fig. 1. Note that, at first sight, the durations of the experimental startups can look rather, long but this is not a requirement of the proposed methodology; previous works have proven that, provided by the startup duration is longer than 1 second, the methodology is perfectly valid [21] and most industrial motors startups have longer durations.

A detailed analysis of these time-frequency graphs enables to reach the following conclusions:

With regards to the time-frequency analyses of the emf signal induced under starting in the air-core flux sensor, note that the differences between the healthy condition and the faulty ones are very evident even at first sight. As observed, additional components appear in these latter two cases, in comparison with the healthy case. For the healthy field winding, note that only the evolutions of the family of harmonics caused by the rotor saliency (given by (2)) are observed. These are the components whose theoretical evolutions were depicted in blue color in Fig.1. Especially clear are the components raising for $k_{2}=-1, k_{2}=+1$ and $k_{2}=-2$. Also, other rotor saliency components such as $f \cdot(1+2 \cdot s)$ are clearly observed (decreasing from $150 \mathrm{~Hz}$ to near $50 \mathrm{~Hz}$ ). Note that for the healthy field winding, there are very slight traces of the components given by (1) and depicted in red in Fig.1. Only the component $f_{f}$ for $k_{l}=1$ is observable. The absence of most of the fault components given by (1) is logical, taking into account that the winding is heathy; the presence of traces of $f_{f}$ for $k_{l}=-1$ is justified by the fact that this component can be slightly amplified due to misalignments or small eccentricities in the machine.

For the faulty cases (added resistance of $2.7 \Omega$ and short-circuited pole), much more additional evolutions appear in the time-frequency maps. Interestingly, many components linked with the fault appear and evolve according to the theoretical starting evolutions depicted in Fig. 1 (red color). More specifically, the evolutions of the components obtained from (1) for values of $k_{l}= \pm 1$, $k_{l}= \pm 2, k_{l}= \pm 3, k_{l}= \pm 4, k_{l}= \pm 5, k_{l}= \pm 6, k_{l}= \pm 7$ and $k_{l}= \pm 8$ are observable. The fact of detecting so many evolutions caused by the field winding failure, all of them following the predicted evolutions, is a robust evidence of the presence of the fault. Note how the intensity of these components seems higher for the short-circuited pole case, which is indeed the highest fault severity.

- The graphs corresponding to the time-frequency analyses of the emf signal induced under starting in the iron-core flux sensor are very similar to those of the aircore sensor. The main difference relies on the better observability of most of the fault components evolutions. These are much clearer in comparison with the graphs obtained for the air-core sensor. Note, for instance, how in healthy condition not only the $f_{f}$ component for $k_{l}=-1$ but also that for $k_{l}=+1$ (created by inherent misalignments/eccentricities) are clearly observable. In faulty conditions, the evolutions of all $f_{f}$ components for different values of $k_{1}$ are better identifiable than for the previous sensor. This reveals the better suitability of this sensor for the tracking of fault related harmonics.

- Regarding the analyses of the stator current under starting, the first aspect that should be pointed out is the less rich harmonic content of the time-frequency maps compared to that of the previous stray flux maps. Much fewer harmonic evolutions are detectable both under healthy and under faulty conditions, since only some of the airgap flux harmonics induce corresponding harmonics in the stator current signal. The lower harmonic content of the current analyses implies a lower amount of information for the diagnosis of the fault, in comparison with that obtained from the stray flux analyses.

On the other hand, note that in the stator current timefrequency analyses, the saliency components are clearly observable for all fault conditions. In this regard, the Vshaped evolution of $f \cdot(1-2 \cdot s)$ and the decreasing trajectory of $f \cdot(1+2 \cdot s)$ (from $150 \mathrm{~Hz}$ to $50 \mathrm{~Hz}$ ) are clearly observable in all cases. The main difference between the healthy and fault cases relies on the evolutions of the components deduced from (1) for $k_{l}= \pm 1$ that are visible under faulty condition. However, note how the amplitudes of these components (denoted by the color intensity) is much lower than the equivalent in the strayflux maps. On the other hand, note that the evolutions of the other components obtained from (1) for higher 
values of $k_{l}$ are not clearly visible in the stator current time-frequency maps.

In general terms it can be concluded that the analyses of the emf signals induced by the stray flux (either in air- core or iron-core sensors) yield much more information for the diagnosis of field winding faults than the analysis of the starting stator current.

- Finally, the visualization of the time-frequency maps of
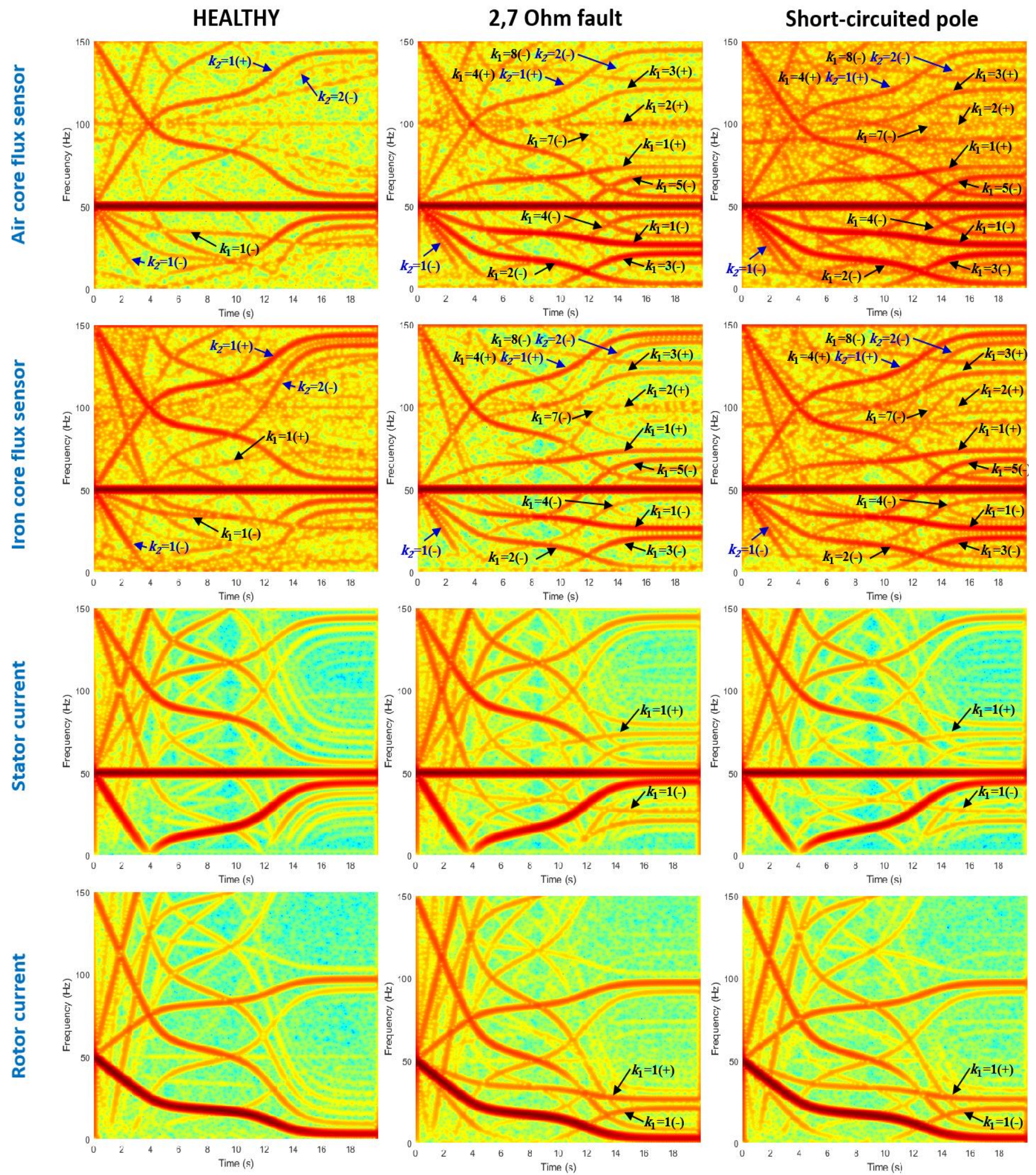

Fig. 5. Time-frequency analyses of the emf induced in air-core sensor, emf induced in iron-core sensor, stator current and rotor current, all of them under an asynchronous starting of an unloaded SM, for: healthy motor (left column), faulty field winding with added resistance=2.7 ohm (middle column) and shorted pole (right column). 
the rotor current under starting also leads to very interesting conclusions. On the first hand, the evolution of the fundamental component of the rotor current $(s \cdot f)$ is clearly visible for all cases: it decreases from the supply frequency $(f)$ to almost zero under starting. On the other hand, there are two main components that appear in the faulty cases but that are absent in the healthy case. These are the components obtained from (1) for $k_{l}= \pm 1$ but referred to the rotor reference frame. These two components are given by expressions (3) and (4), respectively. Note that, under a direct online starting, the component $f_{f}^{\text {rot }}\left(k_{1}=1(-)\right)$ given by (3) decreases from $f_{s}$ (when $s=1$ ) to zero (when $s=1 / 3$ ) and increases again to $f_{s} / 2$ (when $s \approx 0$ ). On the other hand, the component $f_{f}^{\text {rot }}\left(k_{1}=1(+)\right)$ given by $(4)$ evolves between $f_{s}$ (when $s=1$ ) and $f_{s} / 2$ (when $s \approx 0$ ). These evolutions are clearly visible in the graphs and are clear evidences of the presence of the field winding fault.
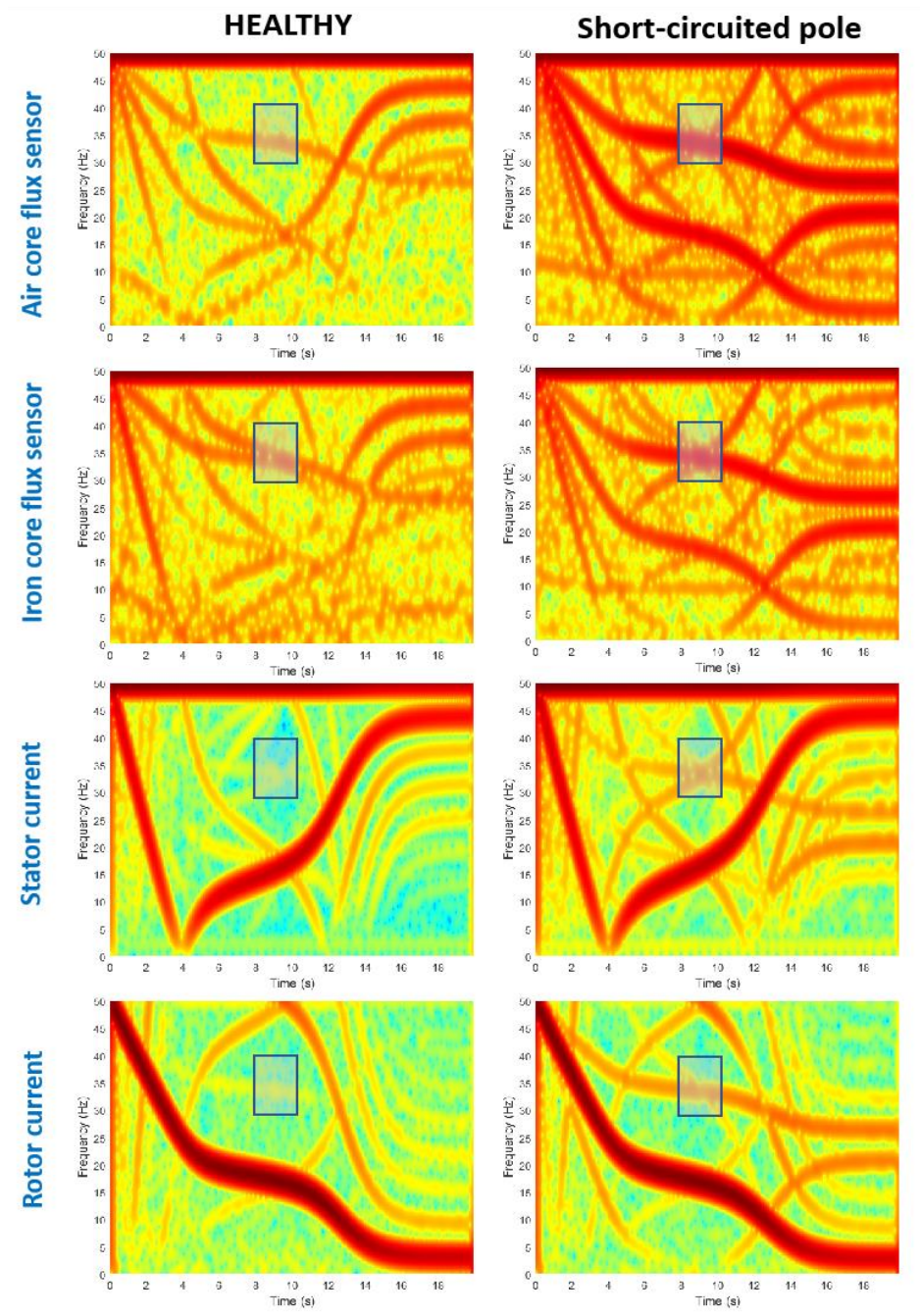

Fig. 6. Areas for computation of proposed indicators in the time-frequency analyses of the: emf induced in air-core sensor, emf induced in iron-core sensor, stator current and rotor current, all of them for an unloaded SM under: healthy motor (left ) and shorted pole (right).

$$
\begin{gathered}
f_{f}^{r o t}\left(k_{1}=1(-)\right)=\frac{f_{s}}{2} \cdot(3 \cdot s-1) \\
f_{f}^{r o t}\left(k_{1}=1(+)\right)=\frac{f_{s}}{2} \cdot(1+s)
\end{gathered}
$$

\section{FAULT SEVERITY INDICATORS}

In order to determine the severity of the failure, fault indicators based in the time-frequency analyses of each of the considered quantities are proposed in this section. The fault indicators are defined on the same basis: a certain area was specified in the corresponding time-frequency map and the indicator was calculated as the maximum energy density (related to that of the fundamental component) detected in that area. The definition of the indicator for a generic area $A$ of the time-frequency map is given by (5) (where $E n_{i, j}$ is the energy density at the $(i, j)$ coordinate of the time-frequency map, $t_{0}$ and $t_{f}$ are, respectively, the initial and final $\mathrm{x}$-samples defining the considered t-f area and $f_{0}$ and $f_{f}$ are, respectively, the initial and final $\mathrm{y}$-samples defining to the considered $\mathrm{t}-\mathrm{f}$ area.

$$
\gamma_{A}=\operatorname{Max}\left(E n_{i, j}\right)_{i=t_{0} \ldots t_{f} ; j=f_{0} \ldots f_{f}}
$$

The areas of the time-frequency maps that are considered in this work for the calculation of the indicators are those shadowed in Fig. 6 for the case of the unloaded SM in healthy condition and with short-circuited pole, respectively. Note that the specified area is trespassed, in each graph, by some of the harmonics amplified by the failure and, more particularly, the fault component obtained for $k_{l}=1$ (-) in the case of flux signals and stator current and $k_{l}=1(+)$ for the case of rotor currents.

In this work, the proposed indicator is applied to both stray flux and current signals. The results of computing the proposed indicator considering the different quantities (emf induced in stray-flux sensors, stator current and rotor current) and for the different fault conditions (healthy motor, faulty with added $\mathrm{R}_{\mathrm{F}}$ $=2.7 \Omega$ and short circuited pole) are specified in Table II for the case of the unloaded SM and Table II (for the loaded SM). In both tables, it is observed a clear increment in the value of the proposed indicators when comparing between healthy and faulty conditions. Note that the increments are very high when the indicator is based on stray-flux signals (increments above $50 \%$ ), whereas they are not so high when the indicator relies on stator or rotor currents. This proves the higher sensitivity of the indicator based on the stray flux regardless of the type of flux sensor that is employed.

Figs. 7 and 8 graphically represent the evolution of the indicators based on the four quantities for the unloaded SM and for the loaded SM, respectively. Note the clear increments of all four indicators when comparing between healthy and fault conditions. Note that the variation between the values of the indicator for the $2.7 \Omega$ fault and the shorted pole is not so significant. The reason is that, under steady-state, the fault condition 1 (added $\mathrm{R}=2,7 \mathrm{ohm}$ ) would be equivalent to the short-circuit of half pole, since half of the current would flow through the added resistance. However, under starting (that is the regime considered in the paper), the rotor inductance yields a current through the resistance that is much higher than half of the current. This causes that the fault severity level 1 (added 
$\mathrm{R}=2,7 \mathrm{ohm}$ ) approaches the fault severity level 2 (shorted pole). Even though, the method is clearly able between healthy and faulty conditions and even some slight differences are observed in the value of the fault indicator for the faulty cases. For all load conditions, the indicators based on stray fluxes (iron core flux sensor and air core flux sensor) are the most reliable, whereas those based on stator or rotor currents are less sensitive. This is logical looking at the time-frequency graphs depicted in Fig.5 since the fault components derived from (1) for $k_{l}=1$ are much more evident in the maps corresponding to the stray flux analyses.

TABLE II.

COMPUTATION OF FAULT SEVERITY INDICATORS BASED ON EACH QUANTITY FOR DIFFERENT FAULT CONDITIONS (UNLOADED SM)

\begin{tabular}{|c|c|c|c|}
\hline \multicolumn{4}{|c|}{ HEALTHY } \\
\hline Quantity & $\begin{array}{c}\text { Time } \\
\text { interval }\end{array}$ & $\begin{array}{c}\text { Frequency } \\
\text { interval }\end{array}$ & INDICATOR \\
\hline Air core flux sensor & $8-10 \mathrm{~s}$ & $30-40 \mathrm{~Hz}$ & -32.48 \\
\hline Iron core flux sensor & $8-10 \mathrm{~s}$ & $30-40 \mathrm{~Hz}$ & -29.92 \\
\hline Stator current & $8-10 \mathrm{~s}$ & $30-40 \mathrm{~Hz}$ & -61.44 \\
\hline Rotor current & $8-10 \mathrm{~s}$ & $30-40 \mathrm{~Hz}$ & -57.7 \\
\hline \multicolumn{4}{|c|}{ FIELD WINDING FAULT (ADDED $\mathrm{R}=2.7 \Omega$ ) } \\
\hline Air core flux sensor & $8-10 \mathrm{~s}$ & $30-40 \mathrm{~Hz}$ & $-13.5(+58.4 \%)$ \\
\hline Iron core flux sensor & $8-10 \mathrm{~s}$ & $30-40 \mathrm{~Hz}$ & $\begin{array}{c}-\mathbf{1 4 . 9 9} \\
(+49.9 \%)\end{array}$ \\
\hline Stator current & $8-10 \mathrm{~s}$ & $30-40 \mathrm{~Hz}$ & $\begin{array}{c}-45.3 \\
(+26.3 \%)\end{array}$ \\
\hline Rotor current & $8-10 \mathrm{~s}$ & $30-40 \mathrm{~Hz}$ & $\begin{array}{c}\mathbf{- 3 8 . 4 9} \\
(+33.3 \%)\end{array}$ \\
\hline \multicolumn{4}{|c|}{ SHORTED POLE } \\
\hline Air core flux sensor & $8-10 \mathrm{~s}$ & $30-40 \mathrm{~Hz}$ & $\begin{array}{c}-\mathbf{1 3 . 3 7} \\
(+\mathbf{5 8 . 8 4 \%}) \\
\end{array}$ \\
\hline Iron core flux sensor & $8-10 \mathrm{~s}$ & $30-40 \mathrm{~Hz}$ & $\begin{array}{c}-14.45 \\
(+51.7 \%)\end{array}$ \\
\hline Stator current & $8-10 \mathrm{~s}$ & $30-40 \mathrm{~Hz}$ & $\begin{array}{c}-44.74 \\
(+27.2 \%)\end{array}$ \\
\hline Rotor current & $8-10 \mathrm{~s}$ & $30-40 \mathrm{~Hz}$ & $\begin{array}{c}\mathbf{- 3 8 . 2 8} \\
(+33.6 \%) \\
\end{array}$ \\
\hline
\end{tabular}

TABLE III.

COMPUTATION OF FAULT SEVERITY INDICATORS BASED ON EACH QUANTITY FOR DIFFERENT FAULT CONDITIONS (LOADED SM)

\begin{tabular}{|c|c|c|c|}
\hline \multicolumn{4}{|c|}{ HEALTHY } \\
\hline Quantity & $\begin{array}{c}\text { Time } \\
\text { interval }\end{array}$ & $\begin{array}{c}\text { Frequency } \\
\text { interval }\end{array}$ & INDICATOR \\
\hline Air core flux sensor & $8-12 \mathrm{~s}$ & $30-40 \mathrm{~Hz}$ & -30.88 \\
\hline Iron core flux sensor & $8-10 \mathrm{~s}$ & $30-40 \mathrm{~Hz}$ & -27.04 \\
\hline Stator current & $8-10 \mathrm{~s}$ & $30-40 \mathrm{~Hz}$ & -60.27 \\
\hline Rotor current & $8-10 \mathrm{~s}$ & $30-40 \mathrm{~Hz}$ & -58.43 \\
\hline \multicolumn{4}{|c|}{ FIELD WINDING FAULT $($ ADDED $\mathrm{R}=2.7 \Omega$ ) } \\
\hline Air core flux sensor & $8-12 \mathrm{~s}$ & $30-40 \mathrm{~Hz}$ & $-8.37(+72.9 \%)$ \\
\hline Iron core flux sensor & $8-12 \mathrm{~s}$ & $30-40 \mathrm{~Hz}$ & $\begin{array}{c}-10.51 \\
(+61.1 \%) \\
\end{array}$ \\
\hline Stator current & $8-12 \mathrm{~s}$ & $30-40 \mathrm{~Hz}$ & $\begin{array}{c}-46.46 \\
(+22.9 \%)\end{array}$ \\
\hline Rotor current & $8-12 \mathrm{~s}$ & $30-40 \mathrm{~Hz}$ & $\begin{array}{c}-39.33 \\
(+32.7 \%)\end{array}$ \\
\hline \multicolumn{4}{|c|}{ SHORTED POLE } \\
\hline Air core flux sensor & $8-12 \mathrm{~s}$ & $30-40 \mathrm{~Hz}$ & $-7.43(+75.9 \%)$ \\
\hline Iron core flux sensor & $8-12 \mathrm{~s}$ & $30-40 \mathrm{~Hz}$ & $\begin{array}{c}-10.35 \\
(+61.7 \%) \\
\end{array}$ \\
\hline Stator current & $8-12 \mathrm{~s}$ & $30-40 \mathrm{~Hz}$ & $\begin{array}{c}-45.81 \\
(+24.0 \%) \\
\end{array}$ \\
\hline Rotor current & $8-12 \mathrm{~s}$ & $30-40 \mathrm{~Hz}$ & $\begin{array}{c}\mathbf{- 3 8 . 3 6} \\
(+34.3 \%) \\
\end{array}$ \\
\hline
\end{tabular}

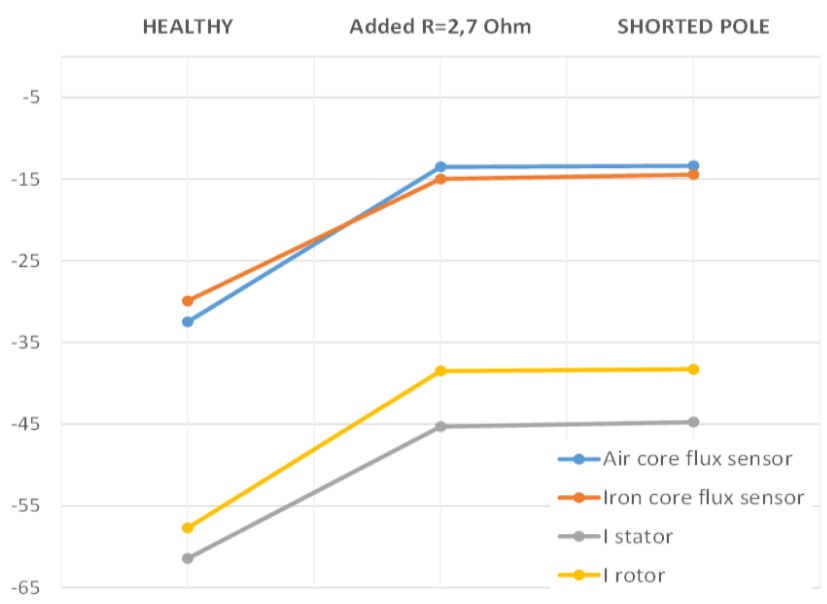

Fig. 7. Evolution of the proposed indicator for the four different quantities under different fault conditions for the unloaded SM.

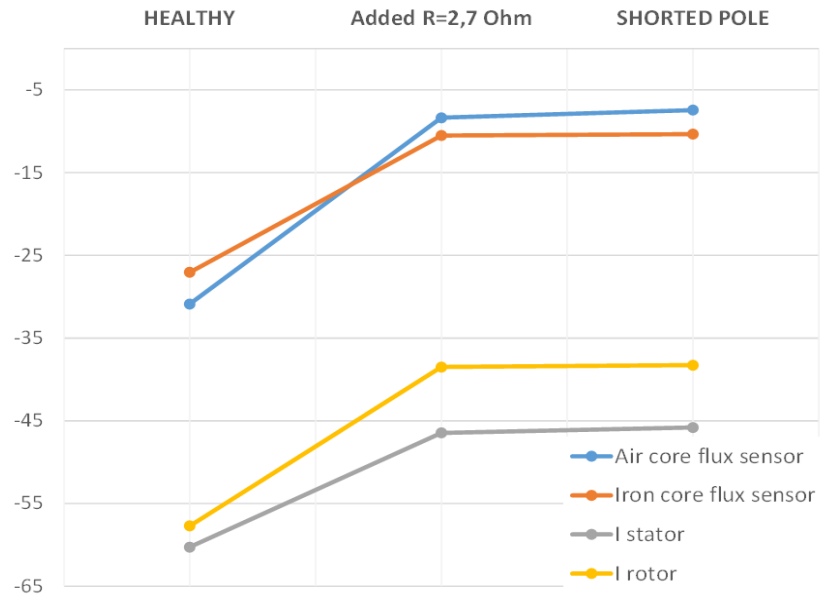

Fig. 8. Evolution of the proposed indicator for the four different quantities under different fault conditions for the loaded SM.

\section{CONCLUSIONS}

This paper compares the analysis of different quantities under starting for the detection of field winding faults in SM. More specifically, the analysis of stray fluxes under transient conditions is compared with that of stator and rotor currents. The idea beyond the proposed approach relies on analyzing the aforementioned transient quantities using time-frequency decomposition tools, which enable tracking the characteristics evolutions of particular harmonics that are amplified by the fault.

Some of the conclusions that are obtained from the application of the proposed methodology are explained next:

- First, the time-frequency maps resulting from the analyses of stray fluxes under starting are much richer that those corresponding to stator or rotor currents. This logical fact implies that the analyses of stray fluxes can provide much more information for the diagnosis of the fault, in comparison with other quantities. 
- In line with the previous fact, the proposed fault severity indicators based on stray fluxes under starting are much more sensitive than those based on currents. This also gives a higher attractive to this quantity.

The results concerning analyses of stray fluxes are quite similar for both sensor configurations used in this work (air core vs. iron core), both with regards to the content of the time-frequency maps and the sensitivity of the stray-flux based indicators. This aspect that confers generality to the obtained results.

- The proposed approach is quite robust since it can be based on the detection of the evolutions of the multiple components amplified by the fault. In particular, the components derived from (1) for $k_{l}= \pm 1$ seem the most reliable since they yield the clearest evolutions under faulty conditions and are the components which suffer the highest amplification when the fault is present.

The proposed methodology is intended to be useful in those applications in which the motor is started with certain frequency. In these cases, the analyses of the considered quantities under starting may be useful to inform on the presence of field winding fault. The application of timefrequency tools to such quantities can be carried out in very short times, provided the high computation capabilities of the microprocessors that are available nowadays, which are much greater than years ago, when the computation of these transforms yielded too long computational times.

\section{REFERENCES}

[1] J. Pyrhönen, T. Jokinen, D.V. Hrabovcová, Design of Rotating Electrical Machines, J. Wiley \& Sons, 2008, pp. 150.

[2] H.W. Beaty, J.L. Kirtley, Jr. Electric Motor Handbook, McGraw-Hill Book Company, 1998, Ch. 5, Pg. 157.

[3] I. Kerszenbaum, Inspection of large synchronous machines: checklists, failure identification, and troubleshooting, Wiley-IEEE Press, Apr. 1996.

[4] P.J. Berry, E.S. Hamdi, "An investigation into damper winding failure in a large synchronous motor," Proc. of Int'l Univ. Power Eng. Conf., pp. 14, 2015.

[5] J. Antonino-Daviu, V. Fuster-Roig, S. Park, Y. Park, H. Choi, J. Park, S.B. Lee, "Electrical Monitoring of Damper Bar Condition in Salient Pole Synchronous Motors without Motor Disassembly," 2019 IEEE 12th International Symposium on Diagnostics for Electrical Machines, Power Electronics and Drives (SDEMPED), Toulouse, France, 2019, pp. 62-68.

[6] J. W. Wood and R. T. Hindmarch, "Rotor winding short detection," IEE Proc. B, Elect. Power Appl., vol. 133, no. 3, pp. 181-189, May 1986.

[7] M. A. El-Sharkawi, R. J. Marks, S. Oh, S. J. Huang, I. Kerszenbaum, A. Rodriguez, "Localization of winding shorts using fuzzified neural networks," IEEE Trans. Energy Convers., vol. 10, no. 1, pp. 140-146, Mar. 1995.

[8] R. L. Stoll and A. Hennache, "Method of detecting and modelling presenceofshortedturnsinDCfieldwindingofcylindricalrotorsynchronous machines using two airgap search coils," IEE Proc. B, Elect. Power Appl., vol. 135, no. 6, pp. 281-294, Nov. 1988.

[9] J. Yun, S. Park, C. Yang, Y. Park, S.B. Lee, M. Sasic, G.C. Stone "Comprehensive Monitoring of Field Winding Short Circuits for Salient Pole Synchronous Motors," in IEEE Transactions on Energy Conversion, vol. 34, no. 3, pp. 1686-1694, Sept. 2019.

[10] R. J. Streifel, R. J. Marks, M. A. El-Sharkawi, and I. Kerszenbaum, "Detection of shorted-turns in the field winding of turbine-generator rotors using novelty detectors-development and field test," IEEE Transactions Energy Conversion, vol. 11, no. 2, pp. 312-317, Jun. 1996.

[11] J.Sottile,F.C.Trutt,andA.W.Leedy,"Condition monitoring of brushless three-phase synchronous generators with stator winding or rotor circuit deterioration," IEEE Trans. Ind. Appl., vol. 42, no. 5, pp. 1209-1215, Sep./Oct. 2006.
[12] F.C. Trutt, J. Sottile, and J.L. Kohler, "Detection of AC machine winding deterioration using electrically excited vibrations," IEEE Transactions Industry Applications, vol. 37, no. 1, pp. 10-14, Jan./Feb. 2001.

[13] J.S. Hsu and J.Stein, "Shaft signals of salient-pole synchronous machines for eccentricity and shorted-field-coil detections," IEEE Trans. Energy Convers., vol. 9, no. 3, pp. 572-578, Sep. 1994.

[14] I. Kerszenbaum and C. Maughan, "Utilization of repetitive surge oscillograph (RSO) in the detection of rotor shorted-turns in large turbinedriven generators," in Proceedings of the Int. Conf. IEEE Electr. Insul., 2011, pp. 398-401.

[15] D.R. Albright, "Interturn short-circuit detector for turbine-generator rotor windings," IEEE Trans. Power App. Syst., vol.PAS-90, no.2, pp.478-483, Mar. 1971.

[16]S. K. Sahoo, P. Rodriguez, and M. Sulowicz, "Comparative investigation of fault indicators for synchronous machine failures," in Proc. Int. Conference on Electrical Machines, ICEM 2014, pp. 1503-1509.

[17] M. Sasic, G. C. Stone, J. Stein, and C. Stinson, "Detecting turn shorts in rotor windings: A new test using magnetic flux monitoring," IEEE Industry Applications Magazine, vol. 19, no. 2, pp. 63-69, Mar./Apr. 2013.

[18] G.C. Stone, I. Culbert, E.A. Boulter, and H. Dhirani ,Electrical Insulation for Rotating Machines - Design, Evaluation, Aging, Testing, and Repair. New York, NY, USA: Wiley, 2014.

[19]Y. Park, H. Choi, J. Shin, J. Park, S. Lee and H. Jo, "Airgap Flux based Detection and Classification of Induction Motor Rotor and Load Defects during the Starting Transient," in IEEE Trans. on Ind. Electronics. 2020.

[20]P. Tian, C. Platero, K. Gyftakis, J. Guerrero, "Stray Flux Sensor Core Impact on the Condition. Monitoring of Electrical Machines," Sensors 2020, 20(3), 749

[21]J. A. Antonino-Daviu, M. Riera-Guasp, J. R. Folch and M. P. M. Palomares, "Validation of a new method for the diagnosis of rotor bar failures via wavelet transform in industrial induction machines," in IEEE Trans. on Industry Appl., vol. 42, no. 4, pp. 990-996, July-Aug. 2006.

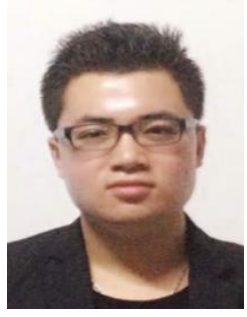

Pengfei Tian was born in Xi'an, Shaanxi, China, in 1991. He received his bachelor degree in Electrical Engineering from Shaanxi Science and Technology University (China) in 2014. He received his Master degree in Electrical Engineering from Universidad Politécnica de Madrid (Spain) in 2018. His research interests include electrical machines condition monitoring and protection.

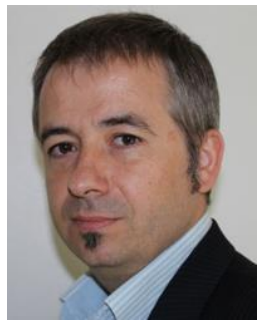

Jose Antonino-Daviu (S'04, M'08, SM'12) received his M.S. and Ph. D degrees in Electrical Engineering, both from the Universitat Politècnica de València, in 2000 and 2006, respectively. Currently, he is Full Professor in the Department of Electrical Engineering of the mentioned University, where he develops his docent and research work. He has been invited professor in Helsinki University of Technology (Finland) in 2005 and 2007, Michigan State University (USA) in 2010, Korea University (Korea) in 2014 and Université Claude Bernard Lyon 1 (France) in 2015. He is IEEE Senior Member since 2012 and he has published over 200 contributions. He is also Associate Editor of IEEE transactions on Industrial Informatics, IEEE Industrial Electronics Magazine and IEEE Journal of Emerging and Selected Topics in Industrial Electronics. He is IEEE IAS Distinguished Lecturer for 2019-20. He was General Co-Chair of IEEE SDEMPED 2013. He received the Nagamori Award from Nagamori Fundation in Kyoto, Japan in 2018. In 2019, He got the SDEMPED Diagnostic Achievement Award for his contributions in electric motors condition monitoring. 


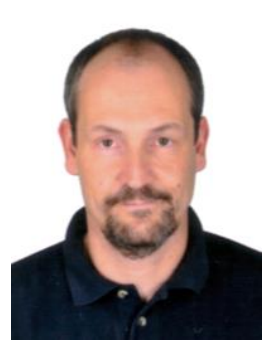

Carlos A. Platero (M'10, SM'20) was born in Madrid, Spain, in 1972. He obtained the Dipl. degree and Ph.D. degree in electrical engineering from the Technical University of Madrid, Spain, in 1996 and 2007 respectively. Since 1996 to 2008 he has worked in ABB Generación S.A., Alstom Power S.A. and ENDESA Generación SA, always involved in design and commissioning of power plants. In 2002 he began teaching at the Electrical Eng. Dep. of the Technical University of Madrid and joined an energy research group. In 2008 he became full-time Associate Professor. During these years he has working in protections and diagnosis of electrical machines, especially large synchronous generators. He has been visiting professor in EPFL (Swiss Federal Institute of Technology Lausanne) 2012/13/14, Coventry University (UK) 2016/18 and Edinburgh University (UK) 2019.

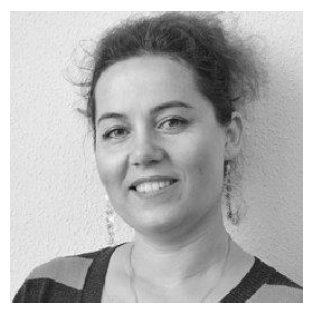

Larisa Dunai (M'19), Associate Professor at UPV, obtained her MSc degree in Electronic Engineering in 2003 from Technical University of Moldova and a Master degree in Electronic Engineering in 2004 at the same university. After obtaining the MSc degree joined the Technical University of Moldova as Assistant professor at the Radio electronics and Telecommunications Department. In 2007 she started working as a researcher in the Research Center in Graphic Technology (CITG) of the Universidad Politecnica de Valencia. In November 2008 she joined the UPV as an Assistant professor of Graphic Design Department. In 2010 obtained her $\mathrm{PhD}$ at Universitat Politècnica de València. In 2013 she received the MIT Innovators Award for Spain and in 2014 the Michael Richey Medal from Royal Institute of Navigation. 